\title{
The Shift from Financial to Non-financial Measures During Transition into Digital Retail - A Systematic Literature Review
}

\author{
Gültekin Cakir, ${ }^{1}$ Marija Bezbradica, ${ }^{1}$ and Markus Helfert ${ }^{1}$ \\ ${ }^{1}$ School of Computing, Dublin City University, Dublin, Ireland \\ \{gueltekin.cakir, marija.bezbradica, markus.helfert\}@dcu.ie
}

\begin{abstract}
Researchers in the retail domain today propose that, in particular, complex and non-financial goals such as 'customer experience' represent the new imperative and leading management objective in the age of Digital Retail, questioning the role of conventional financial measures such as revenue. However, there is no evidence in research showing the corresponding and necessary shift from financial measures to nonfinancial measures as subject of interest in recent years. This article aims to reveal the development of financial versus non-financial metrics used in retail research in the last ten years and thus highlight the transition from conventional retail into Digital Retail from a metrics perspective. A systematic literature review, conducted on the basis of 80 high quality journals, serves as the research method of choice and sheds light on the various range of metrics used in the last ten years of retail research. More importantly, the results still show a major focus on financial measures despite indicating a rising awareness of non-financial, more complex and intangible measures such as 'customer experience' or 'customer satisfaction'. While this finding supports proposed shift towards non-financial measures in current retail research in one side, it also shows a lack of research focusing on non-financial objectives in retail, in comparison to financial measures.
\end{abstract}

Keywords: Omni Channel Retail, Key Performance Indicator, KPI, Customer Experience

\section{Introduction}

With a total revenue generation of around US\$14,1 trillion per year (2017), the significance of today's retail industry is still apparent as it always has been and moreover, it even grew steadily to US\$14,9 trillion in 2018 (Euromonitor 2018).

At the same time, retail is undergoing a major transformation in the process of becoming Digital Retail. Digital Retail can be understood as the digitalisation in the retail industry through digital technologies (Hansen and Sia 2015). Researchers argue that during this transformation, 'customer experience' resembles the new narrative and leading goal for retailers (Briel 2018; Lemon and Verhoef 2016; Pickard 2018; Verhoef et al. 2015) and is considered as a major differentiator for competitive advantage in Digital Retail (Verhoef et al. 2009). However, compared to the conventional retail objectives such as revenue, sales growth or profit, customer experience represents a non-financial, non-monetary and complex objective to measure. Consequently, the transformation in retail also entails a potential transition from financial to non-financial measures. Ideally, this change would be reflected in retail research through emergence of more non-financial measures as subject of interest. In literature, there is no evidence showing this corresponding potential shift and thus providing support for the emergence of more intangible measures, underpinning the change in the retail industry.

Objective of this paper is to investigate the development and use of financial versus non-financial measures throughout retail research in the last ten years. This is done through a systematic literature review on the basis of 80 high quality journals. The outcome will show the relation and significance of financial and non-financial measures in ten years of retail 
research and reveal changes regarding their significance. Moreover, a systematic overview of measures used in retail and retail research will be provided.

This paper is structured as follows: after a brief background and context description in section two, section three outlines how the systematic literature review was conducted. Descriptive results follow and a comprehensive discussion of findings is presented in section four. A conclusion, summarised contributions and future research as well as limitations complete the article in the last section.

\section{Background}

This section discusses and classifies financial and non-financial measures, followed by the related work in this field.

\subsection{Financial and Non-Financial Measures}

In order to manage a business effectively and efficiently, the concept of performance measurement is utilized (Melnyk et al. 2014). This is done through measures quantifying and indicating progress and actions (Neely et al. 1995). Hereby, indicators can be distinguished by their measurability between financial and non-financial measures. Measures are considered as a financial metric in case of its financial nature, or can be measured directly on a monetary basis. For example, 'revenue' can simply be broken down to 'price times goods sold', or 'revenue growth' in percentage (relative measure) can be translated into actual sales (absolute measure). On the other side, non-financial measures are often described as abstract objectives and comprise of intangible, nonmonetary and, in many cases, complex goals such as 'customer experience', 'customer loyalty' or 'customer satisfaction'. They are difficult to measure because of their multidimensional nature (Kranzbühler et al. 2018; Lemon and Verhoef 2016) and are not able to be captured fully by current accounting measures (Ittner and Larcker 1998). Nevertheless, they are also relevant to evaluate progress of actions and to formulate necessary goals for retailers.

Further distinction can be made between strategic and operational measures. If used on top management decision level only, measures are considered as strategic indicators and are characterized by their long-term scope (e.g. year-to-year revenue growth, market share, employee size, change in profitability between time periods, etc.). Strategic measures are abstract and viewed as independent from industry (Zentes et al. 2017) to allow suitable performance comparison for shareholders. Operational indicators can be summed up as measures for evaluating day to day progress of actions such as in inventory management (e.g. stock accuracy, shelf capacity), fulfilment (delivery times, order times, etc.) or store metrics (store profit, salesperson net profit, etc.) (Gunasekaran et al. 2001) as well as metrics used in an e-commerce context (conversion rates, web visits, cost per click, etc.) (Tsai et al. 2013). The classification is shown in the following Table 1, along with examples.

Table 1: Classification of metrics.

\begin{tabular}{|c|c|c|}
\hline Measurability & Management Level & Metric Example \\
\hline \multirow[t]{2}{*}{ Financial } & Strategic & $\begin{array}{l}\text { Retailer's Shareholder Value (e.g. Kashmiri, Nicol, } \\
\text { \& Hsu, 2017) }\end{array}$ \\
\hline & Operational & $\begin{array}{l}\text { Cross Space Elasticity \& Shelf Space (e.g. Schaal \& } \\
\text { Hübner, 2018) }\end{array}$ \\
\hline \multirow[t]{2}{*}{ Non-Financial } & Strategic & $\begin{array}{l}\text { Customer Satisfaction, Customer Loyalty, Service } \\
\text { Quality (e.g. Lin, Luo, Cai, Ma, \& Rong, 2016) }\end{array}$ \\
\hline & Operational & Purchase Likelihood (Ho, Kowatsch, \& Ilic, 2014) \\
\hline
\end{tabular}




\subsection{Related Work}

Related work, covering development or classification of measures in a retail context is scarce. Nevertheless, some authors discuss metrics and metrics classifications.

Table 2: Related work.: Classification of metrics.

\begin{tabular}{|c|c|c|c|}
\hline Authors & Year & Context & Classification of metrics \\
\hline $\begin{array}{l}\text { Gunasekaran } \\
\text { et al. }\end{array}$ & 2001 & Supply Chain & $\begin{array}{l}\text { Financial, non-financial, strategical, } \\
\text { tactical, operational }\end{array}$ \\
\hline $\begin{array}{l}\text { Anand and } \\
\text { Grover }\end{array}$ & 2013 & Supply Chain & Transport, inventory, IT and resources \\
\hline Glanz et al. & 2016 & Retail Food Store & Qualitative and quantitative Indicators \\
\hline Kumar et al. & 2017 & Retail & $\begin{array}{l}\text { Market-related, firm-related, store- } \\
\text { related, customer-related }\end{array}$ \\
\hline
\end{tabular}

For example, from a supply chain perspective, Gunasekaran et al. (2001) developed a framework, comprising strategical, tactical and operational level metrics. The authors argue that there is a need for more balance between financial and non-financial measures, as well as clear distinction between application level (strategic, tactical, operational). However, despite relation to retail, the focus of the study remains strongly oriented towards supply chain. Anand and Grover (2015) also identified and classified retail supply chain key performance indicators, providing a comprehensive overview of measures in the dimensions of transport, inventory, IT and resources. The broad overview gives valuable insights into supply chain operations and measures, however, the focus is not completely retail-related and there is no systematic development about measure evolvement. Glanz et al. (2016) conducted a review about retail food store environment measures concluded with specific and static collection of suitable measures. Although, similar research approach was applied here, the scope and focus are too specific to deduct conclusion for Digital Retail. Kumar et al. (2017) propose an organizing framework for retailers with four dimensions (Market, Firm, Store and Customer) where they map studies related to profitability and list applied measures from those articles. The article shows measures in different manifestations along the above mentioned dimensions (e.g. sales, ROI, MVA, CLV, customer experience or loyalty), however, despite providing an implicit strategic and operational differentiation of measures (strategy and actions), there is no explicit distinction between financial and non-financial measures and a specific timeline comparison or element. Related work is summed up in Table 2.

\section{Method - Systematic Literature Review}

A systematic literature review represents a vital method to extract knowledge and conduct critical reflection considering the vast amount and variety of sources (books, journals, conferences, etc.). Following the review approach as proposed by Webster \&Watson, ensuring high quality and rigour in the reviewing process (Webster and Watson 2002), answers to the following research questions are pursued: (1) "How evolve financial and non-financial retail measures as subject of interest throughout the years in retail research?" and (2) "What measures were subject of interest throughout the years in retail research?".

This section is structured into two parts: (1) review approach and scope, explaining search strategy and process and (2) analysis framework, discussing the concept matrix used for article analysis. 


\subsection{Review Approach and Scope}

This review is conducted in four steps (Fig. 1). We first identified relevant journals on the basis of Scopus, the abstract and citation database of Elsevier. Source material is retrieved from high quality journals covering a wide field of disciplines. We filtered those journals within the 5\% citescore percentile of the database to ensure high level quality, measured by citation quality. Second, we applied a search string on each journal ('search in title and abstract'). The search string utilized "AND" and "OR" Boolean operators to link keywords and was set as follows: "TITLE-ABS-KEY(retail*AND measure* OR performance* OR goal* OR metric* OR KPI OR objective* OR indicator*)" - applied to the subject areas "Business Management Accounting", "Decision Science" and "Information Systems" of the Scopus database to include a wide and relevant coverage of disciplines. The search string covered the keywords "measure" and appropriate synonyms (KPI, metric, indicator). Additionally, it included the terms "performance", "goal" and "objective" to address a context of "performance goal-relationship" in retail research.

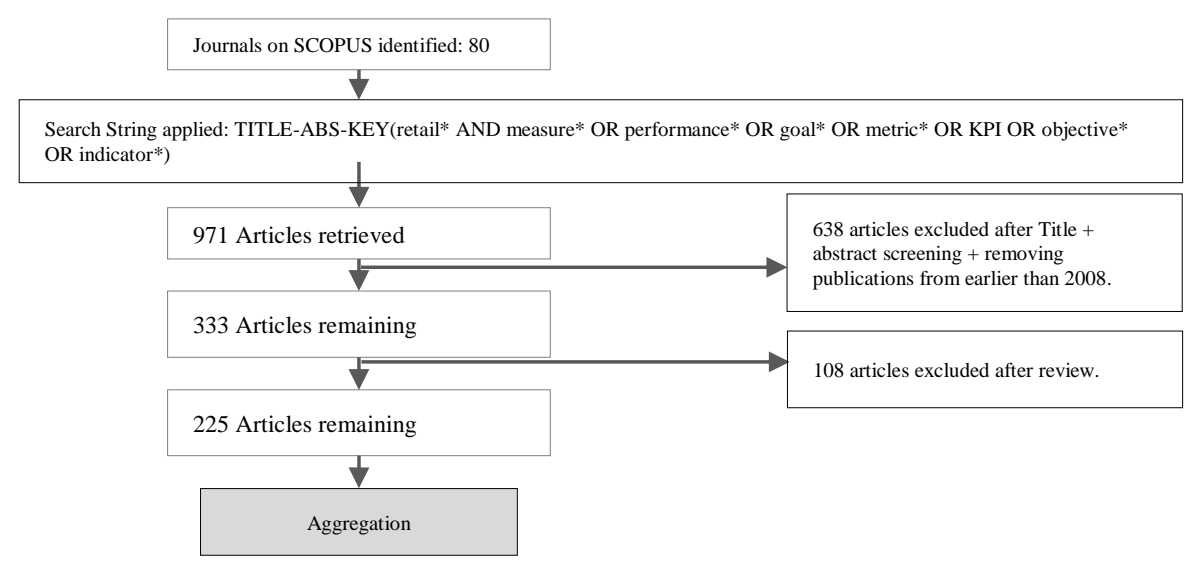

Figure 1: Search Strategy and Selection Process.

Third, all articles published earlier than 2008 were excluded - the review has a scope of ten years to cover an appropriate period of time for reflection. Also, non-English written articles and articles without any relevance on retail industry as the field of research or articles not providing a retail-performance measure-relationship were excluded as well. Excluded was for example a study about customer decision context ("shopper's goals") with no relation and discussion about subsequent retail performance (Guha et al. 2018). In the same step, all abstracts of the remaining articles were screened regarding context. The last step comprised all remaining articles for review and data extraction. Here, articles with no relevance to the research objectives were excluded as well. On- or offline retail focus in articles was treated equally, so there was no distinction between different retail channels in the reviewing process since Digital retail is defined by the merging of on- and offline channels into "omnichannel" to provide a seamless customer experience (Lemon and Verhoef 2016; Verhoef et al. 2015). Research in travel and bank retail was also considered. Inclusion and exclusion criteria are summed up in Table 3. 
Table 3: Inclusion and exclusion criteria for the literature review.

\begin{tabular}{|c|c|}
\hline Inclusion Criteria & Exclusion Criteria \\
\hline 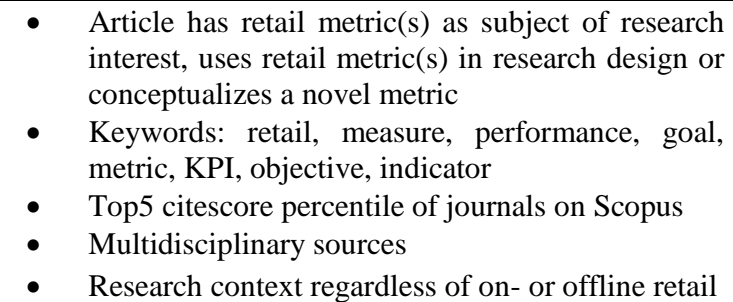 & $\begin{array}{ll}\text { - } & \text { Non-English publication } \\
\text { - } & \text { Publication earlier than } 2008 \\
\text { - } & \text { No relation to retail industry } \\
\text { in research context } \\
\text { - } \\
\text { Not providing a relationship } \\
\text { between measures and } \\
\text { performance }\end{array}$ \\
\hline
\end{tabular}

Results. The journal selection process identified 80 journals out of the relevant research areas. After application of the keyword string to every journal, a total output of 971 articles was generated. Limiting to publications from 2008 year on and after screening of title and abstracts, 638 articles were discarded ( $66 \%)$. Only 333 papers remained to be screened in depth. After reviewing the papers, data out of final 225 articles was extracted (108 articles discarded after reading). Search strategy and selection process is summarized in Fig. 1.

\subsection{Analysis Framework}

The review is structured with the use of a concept matrix (Webster and Watson 2002), where the identified concepts are mapped and complemented to the classification in Table 1 in Sect. 2.1. Articles are screened accordingly and any metric used in research, as a measure of interest, a measure validating a framework or conceptualizing a new measure are looked at and classified accordingly to the criteria in Table 1.

The link between these types of measures lies in the cause-effect-relationship between non-financial and financial drivers. Non-financial drivers can be driven by financial drivers but can also lead to general strategic financial indicators such as Return on Investment or impact on Shareholder Value (Ittner and Larcker 2003). For example, long delivery times of an online retailer can affect customer satisfaction negatively and be reflected by declining sales and thus poor return on investment on shareholder perspectives. The concept matrix is shown in Table 4.

Table 4: Concept matrix.

\begin{tabular}{lllll}
\hline Metric & Financial & Non-Financial & Strategic & Operational \\
\hline Author(s) X & $\mathrm{X}$ & & & $\mathrm{X}$ \\
Author(s) Y & & $\mathrm{X}$ & $\mathrm{X}$ & \\
$\ldots$ & & & & \\
\hline
\end{tabular}

\section{Findings and Discussion}

This section discusses the findings of the review in three parts, beginning with overviews of strategic and operational metrics and following with dynamic results (evolvement of financial/non-financial metrics throughout retail research).

\subsection{Strategic Metrics}


Findings. The majority of strategic financial indicators used in retail research is represented by 'sales'/'revenue', 'profit' and 'return on [investment]-measures' (e.g. return on investment, return on equity) and thus reflect a focus on accounting measures (see Table 5). Some articles use indicators such as 'cash flow' (e.g. in Kalaignanam et al. 2018; Lado et al. 2008) or 'market share' (e.g. in Shee et al. 2018; Srinivasan et al. 2013) and differentiate themselves by applying a liquidity or market related perspective. Regarding non-financial indicators, trust, loyalty, satisfaction and other customer related measures resemble the major part of measures of interest. In addition, quality and image indicators are discussed consistently throughout retail research in the last ten years.

Discussion. The major focus on strategic measures lies in accounting measures. This is probably due to their simple measurability and ease to use and acquire. Non-financial indicators such as "Customer Channel Awareness" (Bell et al. 2018) reflect awareness for Digital Retail peculiarities (different channels in retail). Additionally, a surprising wide variety of articles discuss employee related indicators, showing significance of the organisational element in retail (e.g. leadership (Lee et al. 2011), racial diversity (Richard et al. 2017) or employee orientation (Tang et al. 2014)).

Table 5: Overview of strategic metrics used in retail research from 2008 to 2018.

\begin{tabular}{|c|c|c|}
\hline & Financial Metrics & Non-Financial Metrics \\
\hline Strategic & 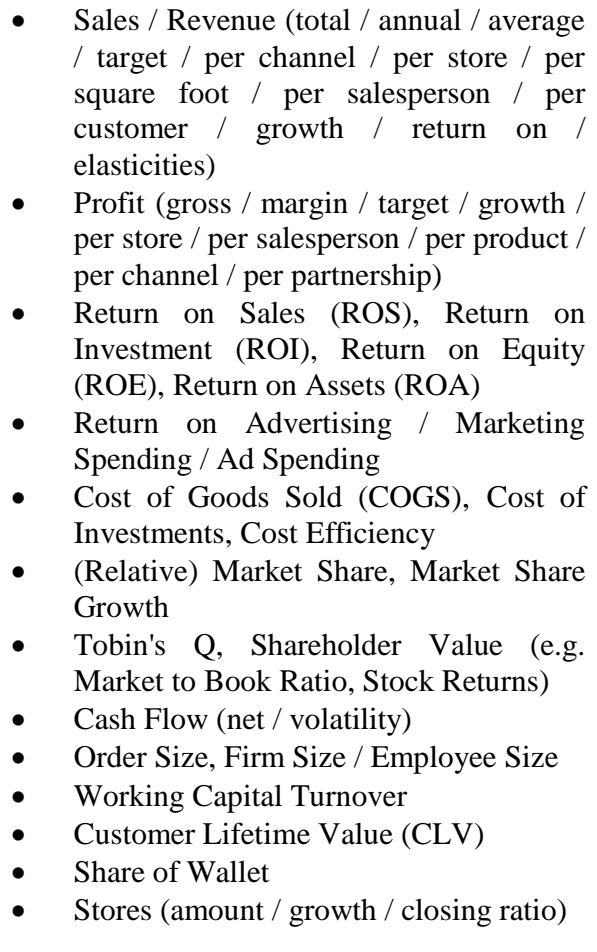 & 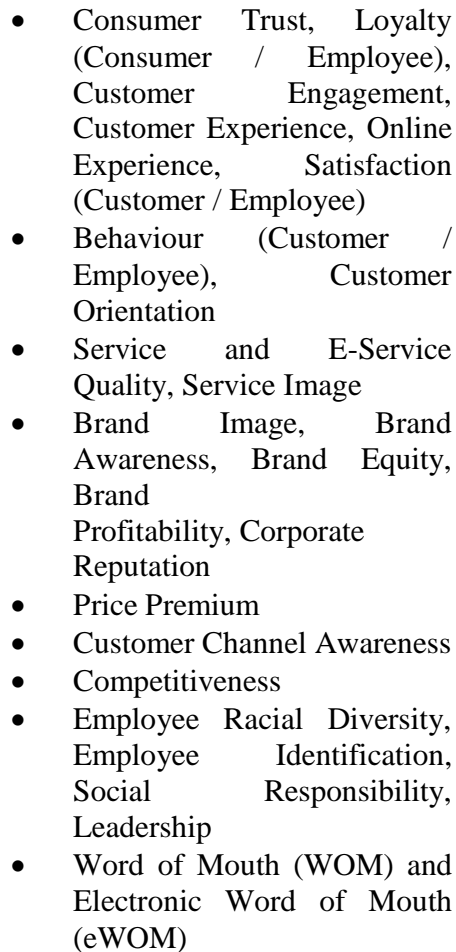 \\
\hline
\end{tabular}

\subsection{Operational Metrics}

Findings. In terms of operational metrics, a variety of financial and non-financial measures were revealed (see Table 6). The majority of the indicators have productivity and/or efficiency purposes. Financial measures are for example represented by inventory performance (e.g. inventory inaccuracy, inventory variance or inventory costs), customer related measures (e.g. complaint rates, customer spending) or e-commerce measures (impression rates, web visits or e-mail response rates). Non-financial measures comprise mainly customer oriented, subjective indicators such as purchase intentions (Berry et al. 2015; Wen and Lurie 2018), likelihoods (Ho et al. 2014) or perceived value (Karpen et al. 2015). 
Discussion. The wide variety signifies the complex nature of operations in retail. Besides established productivity indicators in the domain of supply chain (inventory, delivery, logistics), also web and store performance measures play a role, as well as indicators assessing organisational performance. However, it becomes evident that also non-financial indicators are well established in retail research on operational level.

Table 6: Overview of operational metrics used in retail research from 2008 to 2018.

\begin{tabular}{|c|c|c|}
\hline & Financial Metrics & Non-Financial Metrics \\
\hline Operational & $\begin{array}{l}\text { - } \text { Order Cycle Time } \\
\text { - } \quad \text { (Product) Return Rate } \\
\text { - } \quad \text { Productivity (per store / per salesperson) } \\
\text { - Shelf } \\
\text { - } \quad \text { Shelf Space Capacity, Cross Space Elasticity } \\
\text { - } \quad \text { Purchase Frequency per Customer } \\
\text { - } \quad \text { Click Through Rate, Impression Rates, Web } \\
\text { Visits, Email Response Rates, SEA Price / } \\
\text { Click } \\
\text { - Customer Complaints } \\
\text { Customer Spending (Shopping Basket Size), } \\
\text { Coupon Redemption Rate, Customer Trip } \\
\text { Revenue, Customer Recency Rate, Customer } \\
\text { Cross Buying Rate } \\
\text { Inventory Costs, Inventory Inaccuracy, } \\
\text { Inventory Variance Ratio, Inventory Average } \\
\text { Promotion Costs } \\
\text { - Stock Capacity, Logistics Costs } \\
\text { (transportation / warehousing / procurement) } \\
\text { Demand Forecast, Demand Variance, } \\
\text { Forecasting Period, Lead Time Average } \\
\text { Order Variance Ratio } \\
\text { Salesperson Salary, Share of Wages, } \\
\text { Employee Absenteeism, Labour Hours }\end{array}$ & $\begin{array}{ll}\text { - } & \text { Re)purchase } \\
\text { Intentions } \\
\text { - In-Store Experience } \\
\text { Store Image, Perceived } \\
\text { Showrooming, } \\
\text { Perceived Product } \\
\text { Value } \\
\text { - Customer Referral } \\
\text { Behaviour } \\
\text { - Consumer Goodwill, } \\
\text { Convenience } \\
\text { Ease of Use (Web) } \\
\text { - Purchase Uncertainty, } \\
\text { Purchase Likelihood, } \\
\text { Product Return } \\
\text { Likelihood } \\
\text { Order Fulfillment } \\
\text { Quality } \\
\text { Service Behaviour } \\
\text { Organizational } \\
\text { Climate, Employee } \\
\text { Retention, Employee } \\
\text { Motivation, Employee } \\
\text { Compliance } \\
\text { Behaviour, } \\
\text { Salesperson Emotional } \\
\text { Intelligence }\end{array}$ \\
\hline
\end{tabular}

\subsection{Evolvement of Metrics}

Findings. Overall, the development of metrics along the timeline from 2008 to 2018 shows a general growth in research with retail measures as subject of interest. Here, the increase of nonfinancial measures from 2015 to 2018 can be characterized as the most significant one. Also noteworthy is a peak in 2009, showing a year of high interest for retail measures. The relation between financial and non-financial measures can be described as unequally distributed. The focus in retail research lies in financial measures throughout the scope of the review, shown by a relation of ca. $55 \%$ to $45 \%$ in favour of financial metrics. However, it is observable that the gap is shrinking: in 2017, the interest in non-financial measures rose even more than in financial measures.

Discussion. On the one hand, the development shows a general rising emphasise on articles, incorporating retail measures, but on the other hand, a rising awareness for nonfinancial measures, compared to earlier years of publication, which is most significantly shown in 2018 , is clearly visible. Consequently, findings show indeed a continuous shift towards more non-financial measures in the last ten years (Fig. 2). 


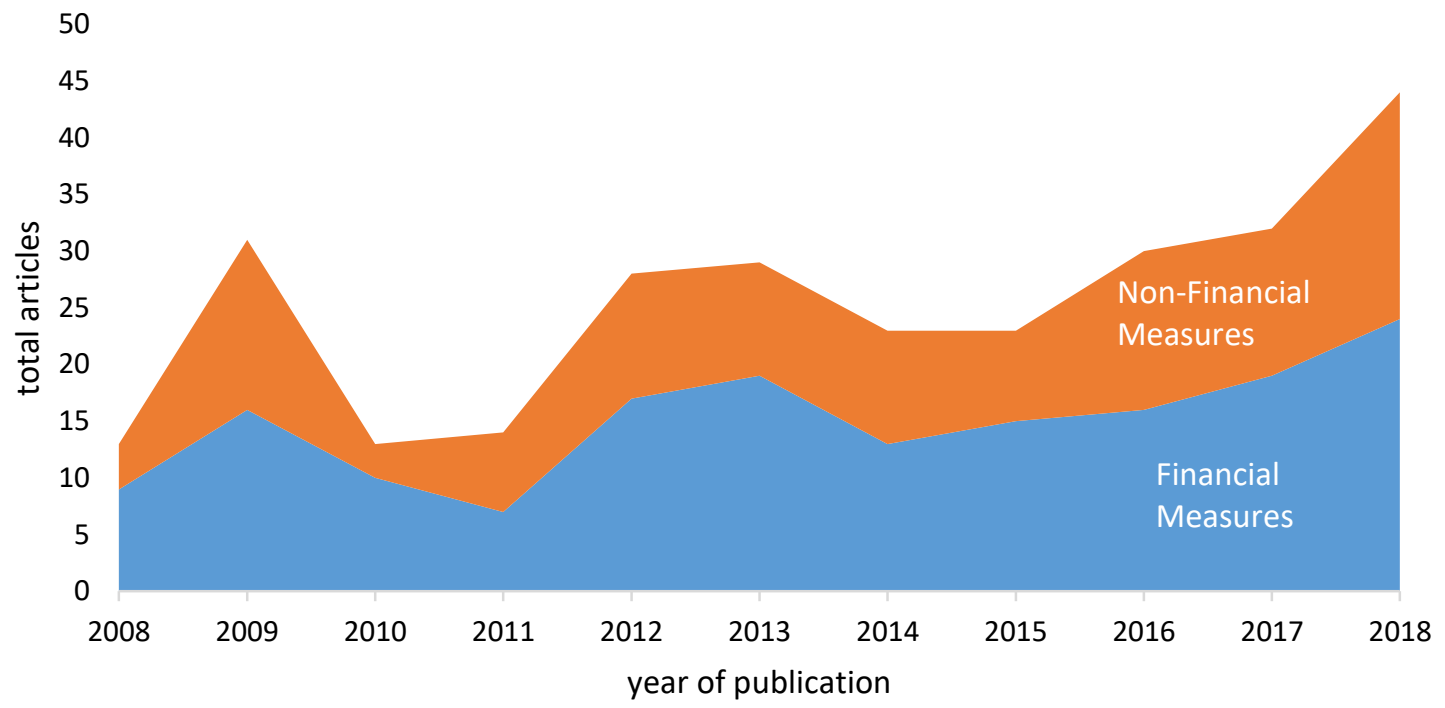

Figure 2:Distribution and Frequency of Financial and Non-Financial Metrics used in Retail Research from 2008 to 2018.

\section{Conclusion}

Following a systematic literature approach, this article investigated the development and forms of financial and non-financial measures throughout retail research in the last ten years to show a shift from financial to non-financial measures. Findings revealed an increase since 2015 in non-financial measures as subject of interest in retail research and support the proposition of authors, arguing the leading and rising role of nonfinancial measures, represented primarily by 'customer experience', in the transformation process of Digital Retail. This finding is also encouraged by rising awareness from the industry perspective. Here, it is observable that, for example, the British multinational retailer TESCO now incorporates the strategic non-financial measure "Group Net Promoter Score" and measures assessing "employee trust" and "recommendation" in their annual reports (Tesco PLC 2018) - these indicators were not communicated before 2014. Another interesting indicator is proposed by KPMG: a new metric, conceptualised as "Experience per Square Foot", emphasises the rising role of "customer experience' in Digital Retail (Pickard 2018). Regarding the second objective of this study, a wide range of different measures used in empirical or conceptual studies were uncovered, synthesised and classified according to strategic and operational level, showing an almost balanced variety between financial and non-financial measures. However, financial measures remain still a focus in retail research so far. A noticeable finding is also given by the emphasise on rather organisational metrics, for example, evaluating employee performance on different dimensions, e.g. satisfaction, service quality, behaviour or simply net profit. Also, other organisational elements such as climate, social diversity or compliance behaviour are metrics of interest. This might appear as an interesting finding, considering the rising role of cultural mindset and organisational capabilities in Digital Retail which are also argued by several authors (Briel 2018; Homburg et al. 2017).

As with similar studies, this study involves limitations. To begin with, this study did not distinguish between on- and offline retail, considering the dissimilarity between retail channels, expressed by different operations and different measures (Beck and Rygl 2015). On one hand, this limitation supports the approach proposed in Digital Retail, namely the merging of channels and focusing on the "omnichannel perspective" as one channel only (Verhoef et al. 2015). On the other hand, it might still be a fruitful research to investigate the evolvement and 
relationship of on- and offline metrics during transition into Digital Retail - findings could uncover new type of metrics emerging. This study can be considered as a first step. Moreover, the study solely relied on one database. Despite Scopus being comprehensive, future investigations could be conducted with more variety of databases to support (e.g. Web of Science). Further limitation is characterised by the fact that this literature review did not pay attention to the potential dilution effect, caused by journal subjects, e.g. Journal of Operations Management, one of the sources in the literature review, focusing on operations only and thus providing mostly operational-related measures in its studies.

\section{Acknowledgements}

This project has received funding from the European Union's Horizon 2020 research and innovation programme under the Marie Skłodowska-Curie grant agreement No. 765395, and was also supported, in part, by Science Foundation Ireland grant 13/RC/2094 and co-funded under the European Regional Development Fund through the Southern \& Eastern Regional Operational Programme to Lero - the Irish Software Research Centre (www.lero.ie).

\section{References}

Anand, N., Grover, N.: Measuring retail supply chain performance - theoretical model using key performance indicators (KPIs). Benchmarking Int. J. 22(1), 135-166 (2015).

Beck, N., Rygl, D.: Categorization of multiple channel retailing in multi-, cross-, and omnichannel retailing for retailers and retailing. J. Retail. Consum. Serv. 27, 170-178 (2015).

Bell, D.R., Gallino, S., Moreno, A.: Offline showrooms in omnichannel retail: demand and operational benefits. Manage. Sci. 64(4), 1629-1651 (2018).

Berry, C., Mukherjee, A., Burton, S., Howlett, E.: A COOL effect: the direct and indirect impact of country-of-origin disclosures on purchase intentions for retail food products. J. Retail. 91(3), 533542 (2015).

Von Briel, F.: The future of omnichannel retail: a four-stage Delphi study. Technol. Forecast. Soc. Chang. 132, 217-229 (2018).

Euromonitor: Euromonitor Retail Market Sizes. Euromonitor International (2018).

Glanz, K., Johnson, L., Yaroch, A.L., Phillips, M., Ayala, G.X., Davis, E.L.: Measures of retail food store environments and sales: review and implications for healthy eating initiatives. J. Nutr. Educ. Behav. 48(4), 280-288.e1 (2016).

Guha, A., Biswas, A., Grewal, D., Bhowmick, S.: An empirical analysis of the joint effects of shoppers' goals and attribute display on shoppers' evaluations. J. Mark. 82, 142-156 (2018).

Gunasekaran, A., Patel, C., Tirtiroglu, E.: Performance measures and metrics in a supply chain environment. Int. J. Oper. Prod. Manage. 21(1/2), 71-87 (2001).

Hansen, R., Sia, S.K.: Hummel's digital transformation toward omnichannel retailing: key lessons learned. MIS Q. Executive 14(2), 51-66 (2015).

Ho, E., Kowatsch, T., Ilic, A.: The sales velocity effect on retailing. J. Interact. Mark. 28(4), 237-256 (2014).

Homburg, C., Jozi, D., Kuehnl, C.: Customer experience management: toward implementing an evolving marketing concept. J. Acad. Mark. Sci. 45, 377-401 (2017).

Ittner, C.D., Larcker, D.F.: Are nonfinancial measures leading indicators of financial performance? An analysis of customer satisfaction. J. Account. Res. 36(1998), 1-35 (1998).

Ittner, C.D., Larcker, D.F.: Coming up short on nonfinancial performance measurement. Harvard Bus. Rev. 81, 88-95 (2003).

Kalaignanam, K., Kushwaha, T., Rajavi, K.: How does web personalization create value for online retailers? Lower cash flow volatility or enhanced cash flows. J. Retail. 94(3), 265-279 (2018).

Karpen, I.O., Bove, L.L., Lukas, B.A., Zyphur, M.J.: Service-dominant orientation: measurement and impact on performance outcomes. J. Retail. 91(1), 89-108 (2015). 
Kashmiri, S., Nicol, C.D., Hsu, L.: Birds of a feather: intra-industry spillover of the target customer data breach and the shielding role of IT, marketing, and CSR. J. Acad. Mark. Sci. 45, 208-228 (2017).

Kranzbühler, A.M., Kleijnen, M.H.P., Morgan, R.E., Teerling, M.: The multilevel nature of customer experience research: an integrative review and research agenda. Int. J. Manag. Rev. 20(2), 433456 (2018).

Kumar, V., Anand, A., Song, H.: Future of retailer profitability: an organizing framework. J. Retail. 93(1), 96-119 (2017).

Lado, A.A., Dant, R.R., Tekleab, A.G.: Trust-opportunism paradox, relationalism, and performance in interfirm relationships: evidence from the retail industry. Strateg. Manag. J. 29(4), 401-423 (2008).

Lee, P.K.C., Cheng, T.C.E., Yeung, A.C.L., Lai, K.: An empirical study of transformational leadership, team performance and service quality in retail banks. Omega 39(6), 690-701 (2011).

Lemon, K.N., Verhoef, P.C.: Understanding customer experience throughout the customer journey. J. Mark. 80(6), 69-96 (2016).

Lin, Y., Luo, J., Cai, S., Ma, S., Rong, K.: Exploring the service quality in the e-commerce context: a triadic view. Ind. Manag. Data Syst. 116(3), 388-415 (2016).

Melnyk, S.A., Bititci, U., Platts, K., Tobias, J., Andersen, B.: Is performance measurement and management fit for the future? Manag. Account. Res. 25(2), 173-186 (2014).

Neely, A., Gregory, M., Platts, K.: Performance measurement system design - a literature review and research agenda. Int. J. Oper. Prod. Manag. 15(4), 80-116 (1995).

Pickard, T.: KPMG - Global retail trends 2019. Global retail trends 2019 (2018).

Richard, O.C., Stewart, M.M., Mckay, P.F., Sackett, T.W.: The impact of store-unit-community racial diversity congruence on store-unit sales performance. J. Manag. 43(7), 2386-2403 (2017).

Schaal, K., Hübner, A.: When does cross-space elasticity matter in shelf-space planning? A decision analytics approach. Omega 80, 135-152 (2018).

Shee, H., Shah Jahan, M., Fairfield, L., Nyoman, P.: The impact of cloud-enabled process integration on supply chain performance and firm sustainability. Supply Chain Manag. Int. J. 23(6), 500-517 (2018).

Srinivasan, R., Sridhar, S., Narayanan, S., Sihi, D.: Effects of opening and closing stores on chain retailer performance. J. Retail. 89(2), 126-139 (2013).

Tang, C., Liu, Y., Oh, H., Weitz, B.: Socialization tactics of new retail employees: a pathway to organizational commitment. J. Retail. 90(1), 62-73 (2014).

Tesco PLC: Welcome to our Annual Report (2018).

Tsai, J.Y., Raghu, T.S., Shao, B.B.M.: Information systems and technology sourcing strategies of eRetailers for value chain enablement. J. Oper. Manag. 31(6), 345-362 (2013).

Verhoef, P.C., Kannan, P.K., Inman, J.J.: From multi-channel retailing to omni-channel retailing introduction to the special issue on multi-channel retailing. J. Retail. 91(2), 174-181 (2015).

Verhoef, P.C., Lemon, K.N., Parasuraman, A., Roggeveen, A., Tsiros, M., Schlesinger, L.A.: Customer experience creation: determinants, dynamics and management strategies. J. Retail. 85(1), 31-41 (2009).

Webster, J., Watson, R.T.: Analyzing the past to prepare for the future: writing a literature review. MIS Q. 26(2), xiii-xxiii (2002).

Wen, N., Lurie, N.H.: The case for compatibility: product attitudes and purchase intentions for upper versus lowercase brand names. J. Retail. 94(4), 393-407 (2018).

Zentes, J., Morschett, D., Schramm-Klein, H.: Strategic Retail Management - Text and International Cases, 3rd edn. Springer, Wiesbaden (2017). 